\title{
Green Synthesis of Nano-Liposomes Containing Bunium Persicum and Trachyspermum Ammi Essential Oils Against Trichomonas Vaginalis
}

\author{
Farzaneh Mirzaei \\ Shahid Sagoughi \\ Roghayeh Norouzi ( $\square$ roghayehnorouzi123@gmail.com ) \\ University of Tabriz \\ Abolghasem Siyadatpanah \\ Birjand University of Medical Sciences \\ Bibi Fatemeh Haghirosadat \\ Fatemeh Rezaei \\ Mazandaran University of Medical Sciences \\ Veeranoot Nissapatorn \\ Walailak University \\ Watcharapong Mitsuwan \\ Walailak University \\ Muhammad Nawaz \\ Imam Abdulrahman Bin Faisal University College of Medicine \\ Maria L. Pereira \\ Universidade de Aveiro \\ Seyed Abdollah Hosseini \\ Mazandaran University of Medical Sciences \\ Mahbobeh Montazeri \\ Mazandaran University of Medical Sciences \\ Mohammad Majdizadeh \\ Yazd University
}

Shahid Sadoughi University of Medical Sciences and Health Services Yazd Research and Clinical Centre for Infertility

\section{Research}

Keywords: Trichomonas vaginalis, Bunium persicum, Trachyspermum ammi, Essential oil, and Nano-liposomes

Posted Date: June 5th, 2020

DOI: https://doi.org/10.21203/rs.3.rs-32930/v1

License: (c) (1) This work is licensed under a Creative Commons Attribution 4.0 International License. Read Full License 


\section{Abstract}

Background: Trichomonas vaginalis, a parasitic flagellated protozoan, is one of the main non-viral sexually-transmitted diseases worldwide. Treatment options for trichomoniasis are limited to nitroimidazole compounds. However, resistance to these drugs has been reported, which requires the development of new anti-Trichomonas agents that confer suitable efficacy and less toxicity.

Methods: In the present work, we assessed the effectiveness of the liposomal system containing essential oils of Bunium persicum and Trachyspermum ammi against $T$. vaginalis in vitro. Liposomal vesicles were prepared with phosphatidylcholine (70\%) and cholesterol (30\%) using the thin-film method. The essential oils of $B$. persicum and T. ammi were loaded into the liposomes using the inactive loading method. Liposomal vesicles were made for two plants separately. Their physicochemical features were tested using Zeta-Sizer, AFM and SEM. The anti-Trichomonas activity was determined after 12 and 24 hours of parasite cultures in TYI-S-33 medium.

Results: After 12 and 24 hours of administration, the $\mathrm{IC}_{50}$ of the $B$. persicum essential oil nano-liposomes induced $14.41 \mu \mathrm{g} / \mathrm{mL}$ and $45.19 \mu \mathrm{g} / \mathrm{mL}$, respectively. The $\mathrm{IC}_{50}$ of $T$. ammi essential oil nano-liposomes induced $8.08 \mu \mathrm{g} / \mathrm{mL}$ and $25.81 \mu \mathrm{g} / \mathrm{mL}$, respectively.

Conclusions: These data suggested that nano-liposomes of the essential oils of $B$. persicum and $T$. ammi may be a promising alternative to current treatments for Trichomonas infection.

\section{Background}

Trichomonas vaginalis ( T. vaginalis), a flagellated parasitic protozoan, is one of the leading non-viral sexually-transmitted infections worldwide, with approximately 248 million new cases detected annually causing trichomonosis [1]. However, most infected women and men are asymptomatic, can infect the urethra and prostate in men and serious sequelae in women and more susceptible to infection by the human immunodeficiency virus (HIV) infection in men and women [2-4]. In addition, T. vaginalis has been associated with severe consequences, such as adverse pregnancy outcomes and preterm birth, infertility, predisposition to cervical cancer, premature rupture of membranes and pelvic inflammatory disease [5]. Moreover, this parasite can cause intellectual disability in children and respiratory and vaginal infections in neonates [6-9].

Treatment options for trichomoniasis are limited to nitroimidazole compounds. However, treatment failure occurs, mainly due to significant gastrointestinal adverse effects, which disappear after treatment. In addition, resistance to metronidazole has been reported in at least $5 \%$ of clinical cases of trichomoniasis, which could lead to higher and sometimes toxic doses in these patients. Consequently, potent new alternatives with low toxicity against $T$. vaginalis are urgently needed [10-11].

In recent years, there have been growing studies of the therapeutic potential of natural or herbal products. Medicinal plants are generally considered to be safe and have low toxicity compared to synthetic drugs [12]. Bunium persicum and its derivatives have reported multi-pharmacological effects, including antimicrobial, antioxidant, anti-inflammatory, Antinociceptive, antidiabetic, antifungal and antibacterial [13-18]. Trachyspermum ammi has impressive biological and pharmacological properties, including antimicrobial, antihyperlipidemic, anthelmintic, antibacterial and insecticidal activities [19-23].

Liposomes, small vesicles produced by the dispersion of phospholipids in the aqueous medium, trap the aqueous medium between their closed concentric spheres of the phospholipid membranes [24-25]. Liposomes can contain hydrophilic and lipophilic drugs [26]. In addition, they are endurable and safe in clinical trials, and some formulations have been approved by the FDA [27-28]. Some methods are generally used to prepare liposomes for diagnosis and drug delivery purposes [29]. Phospholipid vesicles enhance the penetration of compounds incorporated and/or encapsulated in them.

These liposomes containing essential oils with greater permeability and concentrations, and then address concerns such as side effects, low drug solubility in water, and lack of proper drug delivery to protozoa. In the present study, the nano-liposomal lipid carriers of essential oils of $B$. persicum and $T$. ammi were used against $T$. vaginalis in vitro.

\section{Methods}




\section{Plant collection}

1. persicum and T. ammi were collected from the mountain Bahabad, located in the Province of Yazd, in Iran, and their species were identified and authenticated in the botanical section of the Yazd Agricultural Research Center, with the voucher numbers 1141 and 24985, respectively. The seeds of B. persicum and T. ammi were harvested, dried, and mechanically powdered using an electrical blender. The whole dry of two plants was dissolved in distillated water $(250 \mathrm{~mL})$ overnight at room temperature using Clevenger apparatus and after 4 hours the yield was used.

\section{Standard calibration Curves of B. persicum and T. ammi (Essential Oils)}

To perform the calibration curve, $1 \mathrm{mg} / \mathrm{mL}$ of $B$. persicum and $T$. ammi was prepared in methanol. Then, different dilutions of essential oils in isopropyl and PBS buffer (phosphate buffered saline) were prepared. The absorption spectra of each dilution were measured by a spectrophotometer (Carry 100 Bio Co. Varian, Victoria, Australia). The experiment was repeated three times, the standard diagram of the essential oils of B. persicum and T. ammi was drawn and then the calibration chart of essential oils of $B$. persicum and T. ammi was drawn in isopropyl solvent and PBS.

\section{Preparation of liposomal systems containing essential oils of B. persicum and T. ammi}

The liposomal system containing essential oils was prepared by thin-layer coating with a combination of soybean phosphatidylcholine (70\%), and cholesterol (30\%). Soybean phosphatidylcholine choline, cholesterol and essential oil were dissolved in a chloroform solvent at $45^{\circ} \mathrm{C}$ on a rotary (Heidolph Instruments $\mathrm{GmbH} \& \mathrm{Co}$. KG, Schwabach, Germany) and dried under vacuum. Hydration was then performed by adding sterile distilled water for one hour at $55^{\circ} \mathrm{C}$. The prepared nano-liposomes were then reduced in size using a bath sonicator for 40 minutes. At the end of the mixture, the size reduction was filtered using 0.45 and $0.20 \mu \mathrm{m}$ filters to homogenize the constituent particles.

\section{Determination of essential oil loading percentage in liposomal systems}

Liposomes containing essential oils were inserted into the dialysis bag after size reduction and filtration and incubated with distilled water for 4 hours at $4^{\circ} \mathrm{C}$ to remove the free and uninspired essential oil. Liposomes were mixed with 1:20 isopropyl to break the lipid wall around the essential oil and release the essential oil. The amount of essential oil absorbed in the liposomal system was determined by a wavelength spectrophotometer. Finally, using the following relationship, the percentage of $B$. persicum and T. ammi load of essential oils in liposomal systems was determined separately.

Encapsulation effciency $(9 \%)=\frac{\text { essential oil in liposome }(\mathrm{mg})}{\text { Total of essential oil }(\mathrm{mg})} \times 100 \mid$

\section{Essential oils release from liposomal systems}

The release of essential oils from liposome system was performed by the dialysis bag method. In this method, liposomes containing the essential oils were poured into the dialysis bag and placed in the vicinity of the PBS buffer at $35^{\circ} \mathrm{C}$ and $\mathrm{pH}=6$ for 24 hours. The absorbance was read by spectrophotometer $(570 \mathrm{~nm})$ and based on this, the release chart of liposome essential oils was drawn. All steps were performed separately to release from the liposome system containing B. persicum and $T$. ammi.

\section{Size and zeta potential characterization of essential oils in liposomal systems}

The particle size distribution range, as well as particle size peak, was determined using Dynamic Light Scattering (DLS), by nanosizer (Brookhaven Instruments Corp, NY, USA). Nano-liposomes were measured at an angle of 90 degrees and laser light irradiation at $657 \mathrm{~nm}$ at $25^{\circ} \mathrm{C}$ was used. The sample was prepared diluted to $0.1 \mathrm{mg} / \mathrm{mL}$. Measurements were performed immediately after preparation. Samples were measured 3 times and each time for 30 seconds. In addition, surface charges (zeta potential) of nano-liposomes containing essential oils were measured by Zeta Sizer (Brookhaven Instruments Corp, NY, USA).

\section{Morphology of liposomal systems containing essential oils}


The liposomal system was imaged using an Atomic Force Microscope (AFM: Nano wizard II, JPK instruments, Berlin, Germany) to confirm the formation of essential oil-bearing nano-liposomes containing essential oil. In addition, $25 \mu \mathrm{L}$ of liposome sample was poured onto a slide and air dried. Samples were then coated with gold for a few seconds to be conductive. At the end, the surface morphology of the nano-carriers (roughness, shape, smoothing and mass) was investigated using a Scanning Electron Microscope (SEM: EM3200, KYKY Technology Development Ltd, Beijing, China).

\section{Cytotoxicity studies by MTT assay}

The cytotoxicity of the empty liposomal system was determined by the MTT assay. To measure toxicity, cells were cultured separately at $1 \times 10^{4}$ cells in a 96-well plate for 24 hours. Healthy human foreskin fibroblast (HFF) cells were then treated with the same volume of fresh culture medium. Then, HFF fibroblasts were cultured in four replicates at 100 and $10 \mu \mathrm{g} / \mathrm{mL}$, respectively, and incubated again for 48 hours. Then, $20 \mu \mathrm{L}$ of MTT solution at a concentration of $5 \mathrm{mg} / \mathrm{mL}$ were added to each well and incubated for 3 hours. The supernatant was then removed and $150 \mu \mathrm{L}$ of DMSO was added to dissolve the Formosan crystals. At each step, centrifugation was performed to remove the liquid. The absorbance was recorded at $570 \mathrm{~nm}$ using a spectrophotometer. Finally, cell viability was calculated according to the relationship below:

\section{Mean optical absorption in the test group - Average light absorption in culture medium Mean optical absorption in control group - Average light absorption in culture medium}

\section{Determination of $\mathrm{IC}_{50}$ nano-liposomes containing essential oil on $T$. vaginalis}

The strain of $T$. vaginalis was isolated from the vaginal discharge of a 34-year-old woman with a confirmed diagnosis of trichomoniasis. This study was approved by the ethical committee of the University Of Medical Sciences Of Isfahan, Isfahan Province, Iran (Ref. No. 1396.851) to obtain human biological samples. The parasite isolate was cultured in TYI-S-33 medium and incubated at $37^{\circ} \mathrm{C}$ until reaching the number of parasites in the logarithmic phase. Smears were prepared to determine the number of parasites. The parasitic strain of the logarithmic phase was then exposed to different concentrations of $B$. persicum and $T$. ammi nano-liposomes at a concentration of 100,000 per $\mathrm{mL}$ (grouped according to Table 1).

Table 1

Effects of B. persicum and T. ammi nano-liposomes against T. vaginalis

\begin{tabular}{|lll|}
\hline $\begin{array}{l}\text { Number of } \\
\text { groups }\end{array}$ & TYS-I-33 medium culture group & $\begin{array}{l}\text { Final concentration of } B \text {. persicum and } T \text {. ammi nano- } \\
\text { liposomes }(\mu \mathrm{g} / \mathrm{mL})\end{array}$ \\
\hline $\begin{array}{l}\text { Negative } \\
\text { control }\end{array}$ & Containing unexposed parasites & - \\
\hline $\begin{array}{l}\text { Positive } \\
\text { control }\end{array}$ & $\begin{array}{l}\text { Containing the parasite }(T . \text { vaginalis }) \text { and } \\
\text { metronidazole }(64 \mu \mathrm{gL})\end{array}$ & 1.95 \\
\hline $\mathbf{1}$ & Contains the parasite & 3.9 \\
\hline $\mathbf{2}$ & Contains the parasite & 7.81 \\
\hline $\mathbf{3}$ & Contains the parasite & 15.62 \\
\hline $\mathbf{4}$ & Contains the parasite & 31.25 \\
\hline $\mathbf{5}$ & Contains the parasite & 62.5 \\
\hline $\mathbf{6}$ & Contains the parasite & 125 \\
\hline $\mathbf{7}$ & Contains the parasite & 250 \\
\hline $\mathbf{8}$ & Contains the parasite & 500 \\
\hline $\mathbf{9}$ & Contains the parasite & 1000 \\
\hline $\mathbf{1 0}$ & Contains the parasite & \\
\hline
\end{tabular}


All groups were kept at $37^{\circ} \mathrm{C}$ and after 12 and 24 hours the number of live parasites was counted by Trypan blue using a Neubauer smear and light microscope (Haemocytometer method). Growth inhibition was calculated for each of the different concentrations (1.95- $1000 \mu \mathrm{g} / \mathrm{mL}$ ) of liposome-containing essential oils in the parasite strain by the formula $\mathrm{GI}=(\mathrm{a}-\mathrm{b} / \mathrm{a})$. Where a: the number of live parasites in the negative control sample, b: the number of live parasites in the sample containing $B$. persicum and T. ammi nanoliposomes. Then, using SigmaPlot ${ }^{T M} 13$ software, the $50 \%$ inhibitory concentration $\left(\mathrm{IC}_{50}\right)$ was calculated for the above nano-liposomes. It should be noted that all experiments were performed in three replicates separately for liposomal nano-carriers containing essential oils of B. persicum and T. ammi and the results were shown in an average level.

\section{Cellular uptake study}

A total of $10^{5} \mathrm{HFF}$ cells in 6-well plates were grown in a monolayer for 24 hours. Then, the cells with the optimal nano-liposomes formula contained DIL color without essential oil. For the fluorescence of the Newsome system and, to a large extent, $0.1 \% \mathrm{M}$ in the organic phase to dry the structure, the additives were followed by the steps of the thin film method, as described by Alemi A et al, 2018 [30]. Subsequently, fluorescent colored nano-liposomes attached to the DIL. These were incubated with essential oils for 3 hours and washed with PBS. Subsequently, the 95\% alcoholic solution was stabilized and the nuclei were stained with DAPI (1 $\mathrm{mg} / \mathrm{mL}$ ) for 15 minutes. The cells were harvested and then examined under a fluorescent microscopy (Olympus, Okayama-shi Okayama, Japan).

\section{Statistical analysis}

In this study, all data were recorded, edited, and entered in Excel software (Excel software, New York, USA; https://www.getgrist.com) to plot the results which were reported as mean and standard deviation. Meanwhile, the SigmaPlot ${ }^{\mathrm{TM}}$ 13 software (Systat Software Inc., San Jose, CA, USA) was also used to calculate $\mathrm{IC}_{50}$.

\section{Results}

\section{Essential oils spectroscopy}

For spectrophotometric data, the calibration curves of the essential oils containing $B$. persicum and $T$. ammi were plotted in the isopropyl solvent and PBS. These were shown as $y=0.0179 x+0.1686$ and $y=0.025 x-0.6296$ with a correlation coefficient $\left(r^{2}\right)$ of 0.9962 and 0.9947 for isopropyl solvent and PBS, respectively (Fig. 1S and 2S).

The line diagram equation in the calibration of essential oil containing T. ammi in isopropyl solvent and PBS was $y=4.278 \mathrm{x}+$ 0.1473 and $y=3.6511 x+0.0362$, respectively. The regression coefficient (R2) of the essential oil containing $T$. ammi in the isopropyl solvent and PBS was 0.9985 and 0.9996, respectively (Fig. 2S, 3S, and 4S).

\section{The loading rate of essential oils in the nano-liposomal systems}

Based on the calibration diagram of the essential oils containing B. persicum and T. ammi in isopropyl (Fig. 1S and 3S) and the loading rate of both essential oils in the liposomal systems, were $51.64 \pm 1.24$ and $40.12 \pm 2.71 \%$, respectively.

\section{Patterns of release of essential oils from the nano-liposomal systems}

The release charts for essential oils containing B. persicum and T. ammi from the liposomal system were plotted during 24 hours at $35^{\circ} \mathrm{C}$ and $\mathrm{pH}=6$ based on the calibration chart. Examination of the essential oil release pattern of the liposomal system (Table 2 and 3) shows that the release of the essential oil in the first hours (at 6 hours after release) and the sustained release of the essential oil in the last hours (interval 12 within 24 hours after release), nano-liposomal essential oils containing B. persicum and T. ammi were present in this study. In addition, the release charts for the two types of essential oils were removed from both nanoliposomal systems in 24 hours (100\% release in 24 hours). 
Table 2

The release of the essential oil containing $B$. persicum in PBS

\begin{tabular}{|lllllllllllllll|}
\hline $\begin{array}{l}\text { Time } \\
\text { (hour) }\end{array}$ & 0.5 & 1 & 1.5 & 2 & 2.5 & 3 & 3.5 & 4 & 4.5 & 5 & 6 & 12 & 24 \\
\hline $\begin{array}{l}\% \\
\text { Release }\end{array}$ & 39.17 & 44.42 & 48.47 & 55.16 & 62.39 & 66.99 & 68.42 & 69.09 & 69.32 & 69.59 & 77.79 & 83.61 & 95.25 \\
\hline
\end{tabular}

Table 3

The release of the essential oil containing T. ammi in PBS

\begin{tabular}{|llllllllllllll|l|}
\hline $\begin{array}{l}\text { Time } \\
\text { (hour) }\end{array}$ & 0.5 & 1 & 1.5 & 2 & 2.5 & 3 & 3.5 & 4 & 4.5 & 5 & 6 & 12 & 24 \\
\hline $\begin{array}{l}\% \\
\text { Release }\end{array}$ & 16.55 & 19.62 & 21.41 & 29.11 & 37.12 & 40.07 & 45.84 & 53.03 & 57.84 & 65.74 & 76.42 & 95.82 & 100 \\
\hline
\end{tabular}

Characterization of the size and zeta potential of essential oils in the nano-liposomal systems

The DLS results show that the particle size in the nano-liposomal system of essential oils containing B. persicum and T. ammi, $120.9 \mathrm{~nm}$ and $110.1 \mathrm{~nm}$, respectively (Fig. 1 and 2). In addition, the surface charge (zeta potential) of the nano-liposomal systems of essential oils containing B. persicum and T. ammi was calculated to be $-16.7 \mathrm{mV}$ and $-9 \mathrm{mV}$, respectively (Fig. 3 and 4 ).

The present study led to the production in the nano-liposomal systems of essential oils containing B. persicum and T. ammi. The results showed that the load of essential oils containing B. persicum and $T$. ammi in the nano-liposomal systems was $51.64 \pm 1.24$ and $40.12 \pm 2.71 \%$, respectively.

The particle size and zeta potential were also calculated for the nano-liposomal systems containing $T$. ammi were $110.1 \mathrm{~nm}$ and $-9 \mathrm{mV}$, whereas for $B$. persicum they were $120.9 \mathrm{~nm}$ and $-16.7 \mathrm{mV}$, respectively. The release of essential oils of $B$. persicum and $T$. ammi from the liposomal system was slow in 24 hours. The essential oils from both nano-liposomal systems were released at the end of this period (24 hours).

\section{Nano-liposomal systems containing essential oils morphology}

The morphology on the nano-liposomal systems of both essential oils containing B. persicum and $T$. ammi was investigated by the Atomic Force Microscope (AFM), Scanning Electron Microscope (SEM), and the formation of liposome was confirmed (Fig. 5, 6 and 7). The SEM image shows that the morphology of the constituent particles are liposome systems containing essential oil, are spherical with smooth surface and average particle size from 25 to $40 \mathrm{~nm}$.

In addition to electron microscopy images, it also confirms the formation of liposomal systems, spherical morphology and the appropriate constituent particles of liposomal systems. Cellular studies also showed that the nano-liposomal systems had low toxicity for HFF cells, and the nano-liposomal systems of essential oils containing T. ammi and B. persicum for 24 and 48 hours showed toxicity for the parasite T. vaginalis and were further prevented its growth.

So far, previous studiesave been performed on the production of lipid systems containing drugs and essential oils, each of which investigates different physicochemical factors of lipid systems, including loading efficiency, drug release pattern, particle size and surface charge (zeta potential) [31-32].

This physicochemical index depends on several factors, including the size of the constituent system, the type and molar percentage of phospholipids used in the structure of the liposomal system, the molar percentage of cholesterol used in the structure of the liposomal system and the nature of the loaded material.

In the present study, the amount of essential oils containing B. persicum and T. ammi in the liposomal system was measured as $40.12 \pm 2.71$ and $51.64 \pm 1.24 \%$, respectively. Other studies have yielded similar results, for example, Majdizadeh et al., 2018 , reported loading of essential oil of Mentha piperita by 61.38\% [26]. In addition, Haghiralsadat et al, 2016 reported the loading rate of essential oil of $T$. ammi in the liposomal system as 35.6 7.4 [33]. Other features studied in liposomal systems are the patterns 
of drug release. The present study showed that the release of essential oils of $B$. persicum and $T$. ammi from liposomal systems was slow in 24 hours.

The pattern of release of these essential oils from the liposomal systems shows that, due to the high concentration of essential oils between the liposomal systems and the buffer that surrounds them, the release of essential oils from the system was explosive in the first hours and decreased over with time. This difference in concentration decreased the release of the essential oil and caused the slope of its release chart to tilt to zero [34].

Another important feature evaluated in this study was the level of superficial charge of the liposomal systems, which is one of the factors that influence the stability of the liposome. The greater the surface charge of the liposome system, the greater the chance that the liposomal systems will form and aggregate, and the stability of the liposomal systems will increase. Therefore, given the high surface charge of the liposomal systems performed in the present study, it seems that these systems have acceptable stability [35-37].

\section{Cytotoxicity studies by MTT assayon Human foreskin fibroblasts (HFF) cell line}

The evaluation of the effect of the essential oil-free liposomal system on human foreskin fibroblast (HFF) cells showed that the viability of these cells in the presence of 10 and $100 \mu \mathrm{g} / \mathrm{mL}$ of an empty liposomal system is $96.7 \%$ and $97.2 \%$, respectively. Thus, the empty liposomal system has little toxicity to HFF cell lines (Fig. 8).

Nowadays, the use of herbal compounds for therapeutic purposes has been widespread and numerous studies have been conducted on the effects of herbal compounds on health and treatment. In the present study, after the development of liposomal systems containing essential oils of B. persicum and T. ammi, the cytotoxic effects of the vacuolar system on the HFF cell line and the cytotoxic effects of essential oil systems in T. vaginalis were investigated, with minor effect on the HFF cell line.

\section{$\mathrm{IC}_{50}$ of nano-liposomes containing the essential oil against $T$. vaginalis}

The $\mathrm{IC}_{50}$ of $B$. persicum-containing liposome essential oil was calculated to be $45.19 \mu \mathrm{g} / \mathrm{mL}$ and $14.41 \mu \mathrm{g} / \mathrm{mL}$ in $T$. vaginalis after 12 and 24 hours, respectively. The $\mathrm{IC}_{50}$ value of the nano-carrier containing $T$. ammi essential oil was determined after 12 and 24 hours against the parasite, T. vaginalis, at $25.81 \mu \mathrm{g} / \mathrm{mL}$ and $8.08 \mu \mathrm{g} / \mathrm{mL}$, respectively (Fig. 9 and 10).

\section{Cellular Uptake Study}

Highly successful nano-liposomes cell extract of containing essential oils without fluorescent dyes DIL was synthesized by fluorescent microscopy. According to the Fig. 11, the intensity of green fluorescence in healthy HFF skin cells indicates the cellular uptake of nano-liposomes essential oils, nano-liposomes are well absorbed by the cell. Core-shaped with DAPI color (blue) and colored DIL nanoliposomes (green) were painted.

\section{Discussion}

In 2000, Muelas-Serrano investigated the effects of American herbs extracts on T. vaginalisin vitro. In this study, extracts from Micania cordifolia and Scutia-buafulia from the Asteraceae family and Lobalia neurolarea from Rhamnaceae family had the greatest effect on T. vaginalis [34]. Ziaiye et al. (2006) showed that the methanolic extract of Zataria multiflora Boiss, Myrtus communis and Artemisia aucheri Boiss had similar effects on the growth of $T$. vaginalis [35].

Wachter et al. (2014) investigated the effects of different concentrations of curcumin on T. vaginalis and reported that curcumin had an anti-Trichomonas effect at all concentrations [38]. Jabari et al. (2015) investigated the effects of Chaerophyllum macropodum extract on $T$. vaginalis and reported an inhibitory effect at all concentrations ( 2 to $150 \mathrm{mg} / \mathrm{mL}$ ). As the concentration of the extract increased, the inhibitory effect also increased [39]. Vazini et al. (2017) investigated the effect of the nano-emulsion of the extract of Micana cordifolia on the growth of T. vaginalis and reported that $1000 \mathrm{ppm}$ of nano-emulsion extract resulted in the elimination of $100 \%$ of this parasite [40]. The results of the Vazini et al. (2017), as in the present study, confirm the anti-Trichomonas activity of nano-liposomes containing essential oils. Fakhrieh-Kashan et al. (2017) evaluated the combined anti-Trichomonas effects of Ginger officinale and Verbascum thapsus extracts and reported that these extracts could increase apoptosis in T. vaginalis [41]. 
Majdizadeh et al. (2018) developed a liposomal system containing peppermint essential oil in a thin layer with a particle size of $247 \mathrm{~nm}$, a zeta potential of -34.54 , a loading efficiency of $61.38 \%$ and a slow release at 62 hours [28]. It seems that similarities in the construction of the lipid system, the type of materials used in the lipid system and the nature of the loaded material are some of the factors that supports the results of the present study. In a study of the effect of rosemary on T. vaginalis, Saeidi et al. (2012) reported inhibitory effects on the growth of this parasite at concentrations of 0.0001 and $0.0002 \mathrm{mg} / \mathrm{mL}$ [42]. Recently, Mohammadi et al. (2019) developed a liposomal system that uses ginger essential oil to investigate the antifungal effects of this system and is related to the essential oil containing $95 \mathrm{~nm}$ liposomal system, having significant antifungal effects on Aspergillus parasiticus [43]. This similar finding with our study confirms the antimicrobial activity of lipid systems containing essential oils.

In this study, DIL-liposome solution treatment group, a very weak green signal was detected in the cell cytoplasm, whereas a relatively stronger signal was observed in the T. ammi essence of DIL-liposome and in the DIL-liposome treatment group. A similar uptake pattern has been reported for calcein-loaded liposomes [44], as well as for hyaluronic acid-magnetic-loaded liposomes [45]. It has been reported that liposome can interact with cells by four mechanisms, including endocytosis, adsorption to the cell surface, transfer of liposomal lipids to the cell membrane and lipid-mediated fusion with the intracellular membranes, the main pathways for liposomal internalization $[46,47,48]$. Moreover, factors such as size due to aggregation, surface charge and surface affinity seem to have a major impact on nanoparticle binding to the cell membrane and subsequent cell uptake [49]. The results indicated that the cellular uptake of the nano-liposome by the skin cells was enhanced by the presence of the intensity of fluorescence signal in the skin cells.

\section{Conclusion}

The results showed significantly improvement in the co-entrapment of $B$. persicum and $T$. ammi for the liposomal systems, which had suitable stability, controlled release rate of essential oils, good surface zeta potential and suitable mean diameter $(<50 \mathrm{~nm})$. The results of this study confirmed the appropriate physical and chemical properties of the liposomal of B. persicum and T. ammi, essential oils, and demonstrate for the first time of their high potential in the treatment of Trichomonas infection. Further studies are recommended to gain a better understanding of the mechanisms involved.

\section{Declaration}

\section{Conflict of interests}

None of authors had conflict of interests.

\section{Acknowledgements}

We also would like to thank Project CICECO-Aveiro Institute of Materials, FCT Ref. UIDB/50011/2020 \& UIDP/50011/2020 for the financial support. We would like to thank the staff of the research laboratory at Shahid Sadoughi University of Medical Sciences, Yazd, Iran, for their help and contributions.

\section{Authors' contributions}

FM, BFH and FR conceived, designed the study and conducted the laboratory work. RN and AS analyzed the data and interpreted the results. RN, VN, WM, MN, ML.P, SAH, MM and MM wrote the manuscript. All authors read and approved the final manuscript.

\section{Funding}

This study was supported by the Shahid Sadoughi University of Medical Sciences, Yazd, Iran; Grant number 4027 and Ethics code was 1396.851.

\section{Availability of data and materials}

Data supporting the conclusions of this article are included within the article and its additional files. 


\section{Ethics approval and consent to participate}

All experiments were approved by the local Ethics Committee of Shahid Sadoughi University of Medical Sciences, Yazd, Iran (No. 1396.851).

\section{Consent for publication}

Not applicable.

\section{Competing interests}

The authors declare that they have no competing interests.

\section{Author details}

${ }^{1}$ Department of Parasitology and Mycology, School of Medicine, Shahid Sadoughi University of Medical Sciences, Yazd, Iran. ${ }^{2}$ Department of Pathobiology, Faculty of Veterinary Medicine, University of Tabriz, Tabriz, Iran. ${ }^{3}$ Ferdows School of Paramedical and Health, Birjand University of Medical Sciences, Birjand, Iran. ${ }^{4}$ Medical Nanotechnology \& Tissue Engineering Research Center, Yazd Reproductive Sciences Institute, Shahid Sadoughi University of Medical Sciences, Yazd, Iran. ${ }^{5}$ Department of Parasitology and Mycology, School of Medicine, Mazandaran University of Medical Sciences, Sari, Iran. ${ }^{6}$ School of Allied Health Sciences and Research Excellence Center for Innovation and Health Products (RECIHP), Walailak University, Nakhon Si Thammarat, Thailand. ${ }^{7}$ Department of Nano-Medicine Research, Institute for Research and Medical Consultations (IRMC), Imam Abdulrahman Bin Faisal University, P.O. Box 1982, Dammam 31441, Saudi Arabia. ${ }^{8}$ CICECO-Aveiro Institute of Materials \& Department of Medical Sciences, University of Aveiro, 3810-193 Aveiro, Portugal. ${ }^{9}$ Toxoplasmosis Research Center, Mazandaran University of Medical Sciences, Sari, Iran. ${ }^{10}$ Fatemeh Zahra Hospital, Mazandaran University of Medical Sciences and Health Services, Sari, Iran ${ }^{11}$ Cellular and Molecular Biology, Department of Nano-Biotechnology, Nano-Biotech Foresight Company, Science \& Technology Park of Yazd, Yazd, Iran.

\section{References}

1. Edwards T, Burke P, Smalley H, Hobbs G. Trichomonas vaginalis: Clinical relevance, pathogenicity and diagnosis. Crit Rev Microbiol.2016; 42(3): 406-17.

2. Carlier Y, Truyens C, Deloron P, Peyron F. Congenital parasitic infections: a review. Acta Trop. 2012; 121:55-70.

3. Fox J, Fidler S. Sexual transmission of HIV-1. Antiviral Res. 2010; 85:276-285.

4. Sena AC, Miller WC, Hobbs MM, Schwebke JR, Leone PA, Swygard H. Trichomonas vaginalis infection in male sexual partners: implications for diagnosis, treatment, and prevention. Clin Infect Dis. 2007; 44(1):13-22.

5. Silver BJ, Guy RJ, Kaldor JM, Jamil MS, Rumbold AR. Trichomonas vaginalis as a cause of perinatal morbidity: a systematic review and meta-analysis. Sex Transm Dis. 2014; 41(6):369-76.

6. Carter JE, Whithaus KC. Neonatal respiratory tract involvement by Trichomonas vaginalis: a case report and review of the literature. Am J Trop Med Hyg. 2008; 78(1):17-

7. Mann JR, McDermott S, Barnes TL, Hardin J, Bao H, Zhou L. Trichomoniasis in pregnancy and mental retardation in children. Ann Epidemiol. 2009; 19(12):891-9.

8. Temesvari P, Kerekes A, Tege A, Szarka K, Medicine N. Demonstration of Trichomonas vaginalis in tracheal aspirates in infants with early respiratory failure. J Matern Fetal Neonatal Med. 2002; 11: 347-349.

9. Schwandt A, Williams C, Beigi RH. Perinatal transmission of Trichomonas vaginalis: a case report. J Reprod Med. 2008; 53(1):59-61.

10. Paulish-Miller TE, Augostini P, Schuyler JA, Smith WL, Mordechai E, Adelson ME, Gygax SE, Secor WE, Hilbert DW. Trichomonas vaginalis metronidazole resistance is associated with single nucleotide polymorphisms in the nitroreductase genes ntr4Tv and ntr6Tv. Antimicrob Agents Chemother. 2014; 58:2938 -2943. 
11. De Brum Vieira P, Tasca T, Secor WE. Challenges and Persistent Questions in the Treatment of Trichomoniasis. Curr Top Med Chem.2017; 17(11):1249-1265.

12. Newman DJ, Cragg GM. Natural products as sources of new drugs from 1981 to 2014. J Nat Prod. 2016; 79(3):629-61.

13. Giancarlo S, Rosa LM, Nadjafi F, Francesco M. Hypoglycaemic activity of two spices extracts: Rhus coriaria $L$. and Bunium persicum Boiss. Nat Prod Res.2006; 20(9):882-6.

14. Hajhashemi V, Sajjadi S, Zomorodkia M. Antinociceptive and anti-inflammatory activities of Bunium persicumessential oil, hydroalcoholic and polyphenolic extracts in animal models. Pharm Biol. 2011; 49: 146- 51.

15. Nickavar B, Adeli A, Nickavar A. Analyses of the essential oil from Bunium persicumfruit and its antioxidant constituents. J Oleo Sci. 2014; 63(7):741-6.

16. Sekine T, Sugano M, Majid A, Fujii Y. Antifungal effects of volatile compounds from black zira (Bunium persicum) and other spices and herbs. J Chem Ecol. 2007; 33(11): 2123- 32.

17. Sharafati Chaleshtori F, Saholi M, Sharafati Chaleshtori R. Chemical Composition, Antioxidant and Antibacterial Activity of Bunium persicum, Eucalyptus globulus, and Rose water on Multidrug-Resistant Listeria Species. J Evid Based Integr Med.2018; 23:2515690X17751314.

18. Talei GR, Mosavi Z. Chemical composition and antibacterial activity of Bunium persicumfrom west of Iran. Asian J Chem. 2009; 21 (6): 4749- 54.

19. Bairwa R, Sodha RS, Rajawat B.S. Trachyspermum ammi, Pharmacogn Rev. 2012; 6:56.

20. Dhore SV, Dahake PT, Kale YJ, Kendre SB, Siddiqui AG. Evaluation of antimicrobial efficacy of Trachyspermum ammi(Ajwain) oil and chlorhexidine against oral bacteria: An in vitro study. J Indian Soc Pedod Prev Dent. 2018; 36(4):357-363.

21. Imani-Baran A, Abdollahi J, Akbari H, Jafarirad S, Moharramnejad S. Anthelmintic activity of crude powder and crude aqueous extract of Trachyspermum ammion gastrointestinal nematodes in donkey (Equus asinus): An in vivo study. J Ethnopharmacol. 2020; 10(248):112249.

22. Saleem U, Riaz S, Ahmad B, Saleem M. Pharmacological Screening of Trachyspermum ammifor Antihyperlipidemic Activity in Triton X-100 Induced Hyperlipidemia Rat Model. Pharmacognosy Res. 2017; 9(1): S34-S40.

23. Soni R, Sharma G, Jasuja ND. Essential Oil Yield Pattern and Antibacterial and Insecticidal Activities of Trachyspermum ammiand Myristica fragrans. Scientifica (Cairo). 2016; 1428194.

24. Gregoriadis G, Ryman BE. Fate of protein-containing liposomes injected into rats: An approach to the treatment of storage diseases. Europ J biochem. 1972; 24(3):485-91.

25. Williams A. Transdermal and topical drug delivery: from theory to clinical practice: Pharmaceutical Press London, Pharmacy. Education. 2004; 4: 49-50.

26. Kirjavainen $M$, Urtti A, Jääskeläinen I, Suhonen TM, Paronen P, Valjakka-Koskela R. Interaction of liposomes with human skin in vitro-the influence of lipid composition and structure. Biochimica et Biophysica Acta (BBA)-Lipids and Lipid Metabolism. 1996; 1304(3):179-89.

27. Fries LF, Gordon DM, Richards RL, Egan JE, Hollingdale MR, Gross M. Liposomal malaria vaccine in humans: a safe and potent adjuvant strategy. Proceedings of the National Academy of Sciences. 1992; 89(1):358-62.

28. Schwendener RA. Liposomes as vaccine delivery systems: a review of the recent advances. Therapeutic advances in vaccines. 2014; 2(6):159-82.

29. Aryasomayajula B, Salzano G, Torchilin VP. Multifunctional Liposomes. Methods Mol Biol.2017; 1530:41-61.

30. Alemi A, Reza J. Z, Haghiralsadat F, Jaliani H. Z, Karamallah M. H, Hosseini S. A, et al. Paclitaxel and curcumin coadministration in novel cationic PEGylated niosomal formulations exhibit enhanced synergistic antitumor efficacy. J Liposome Res. 1995; 5: 543-569.

31. Sherry M, Charcosset C, Fessi H, Greige-Gerges H. Essential oils encapsulated in liposomes: a review. J Liposome Res. 2013; 23(4):268-75.

32. El Asbahani A, Miladi K, Badri W, Sala M, Aït Addi EH, Casabianca H, El Mousadik A, Hartmann D, Jilale A, Renaud FN, Elaissari A. Essential oils: from extraction to encapsulation. Int J Pharm. 2015; 483(1-2):220-43. 
33. Haghiralsadat FA, Azhdari MA, Kalantar SM, Naderinezhad SA, Teymourizadeh KE, Yazdani MO, Hashemi MO, Daneshmand FA. Strategy of Improvements in therapeutic index of medicinal herbs of Iranian indigenous: Synthesis and characterization of phospholipid lipid-based vesicles incorporated Trachyspermum copticum. SSU Journals. 2016; 24(6):468-78.

34. Sasani E, Shahi Malmir H, Daneshmand F, Majdizadeh M, Haghiralsadat BF. A new study on synthesize and optimization of PEGylated liponiosomal nanocarriers containing Curcumin for use in cancer chemotherapy. SSU_Journals. 2018; 26(6):52841.

35. Danhier F, Feron O, Préat V. To exploit the tumor microenvironment: passive and active tumor targeting of nanocarriers for anti-cancer drug delivery. J Control Release. 2010; 148:135-146.

36. Honary S, Zahir F. Effect of zeta potential on the properties of nano-drug delivery systems-a review (Part 2). Tropical Journal of Pharmaceutical Research. 2013; 12(2):265-73.

37. Zhao W, Song Zhuang X-RQ. Comparative study of the in vitro and in vivo characteristics of cationic and neutral liposomes. International journal of nanomedicine. Dove Press; 2011; 6:3087.

38. Wachter B, Syrowatka M, Obwaller A, Walochnik J. In vitro efficacy of curcumin on Trichomonas vaginalis. Wiener klinische Wochenschrift. 2014; 126(1):32-6.

39. Yousofi Darani H, Sharafi S.M, Jafari R, Yousefi H. A, Jafari A, Ghanadian M, et al. Effect of Chaerophyllum macropodum extracts on Trichomonas vaginalis in vitro. J Herb Med Pharmacol. 2015; 4: 61-64.

40. Vazini H. Anti-Trichomonas vaginalis activity of nano Micana cordifolia and metronidazole: an in vitro study. Journal of parasitic diseases. 2017; 41(4):1034-9.

41. Fakhrieh-Kashan Z, Arbabi M, Delavari M, Mohebali M, Hooshyar H. Induction of apoptosis by alcoholic extract of combination Verbascum thapsus and Ginger officinale on Iranian isolate of Trichomonas vaginalis. Iranian journal of parasitology. 2018; 13(1):72.

42. Saeidi S, Forgani F, Javadian F, Javadian E. Effects of Rosmarinus officinalis plant extract on Trichomonas vaginalis parasites and Candida albicans under laboratory conditions: An Experimental Study. Gene Cell Tissue. 2019; 6(3):1-6.

43. Mohammadi M, Haghirosadat BF, Ehsani R, Yazdian F, Rashedi H, Jahanizadeh S, Rahmani A. Synthesis, characterization and evaluation of Liponiosome containing Ginger extract as a new strategy for potent antifungal formulation. Journal of Cluster Science. 2019; 1-11.

44. Han S.M, Na Y.G, Lee H.S, Son G. H, Jeon S.H, Bang K. H, et al. Improvement of cellular uptake of hydrophilic molecule, calcein, formulated by liposome. J Pharmace Invest, 2018; 48(5): 595-601.

45. Zheng S, Han J, Le V. H, Park J. O, Park S. Nanohybrid magnetic liposome functionalized with hyaluronic acid for enhanced cellular uptake and near-infrared-triggered drug release. Colloids Surf B Biointerfaces. 2017; 154: 104-114.

46. Szymanowski F, Hugo A. A, Alves P, Simoes P. N, Gómez-Zavaglia A, Pérez P. F. Endocytosis and intracellular traffic of cholesterol-PDMAEMA liposome complexes in human epithelial-like cells. Colloids Surf B Biointerfaces. 2017; 156: $38-43$.

47. Liu Y, Liu J. Adsorption of nanoceria by phosphocholine liposomes. Langmuir. 2016; 32(49): 13276-13283.

48. Yue Z.G, Wei W, Lv P.P, Yue H, Wang L.Y, Su Z.G, et al. Surface charge affects cellular uptake and intracellular trafficking of chitosan-based nanoparticles. Biomacromolecules. 2011; 12(7): 2440-2446.

49. Nandhakumar S, Dhanaraju M.D, Sundar V.D, Heera B. Influence of surface charge on the in vitro protein adsorption and cell cytotoxicity of paclitaxel loaded poly ( $\varepsilon$-caprolactone) nanoparticles. Bull Fac Pharm Cairo Univ. 2017; 55(2): $249-258$.

\section{Figures}




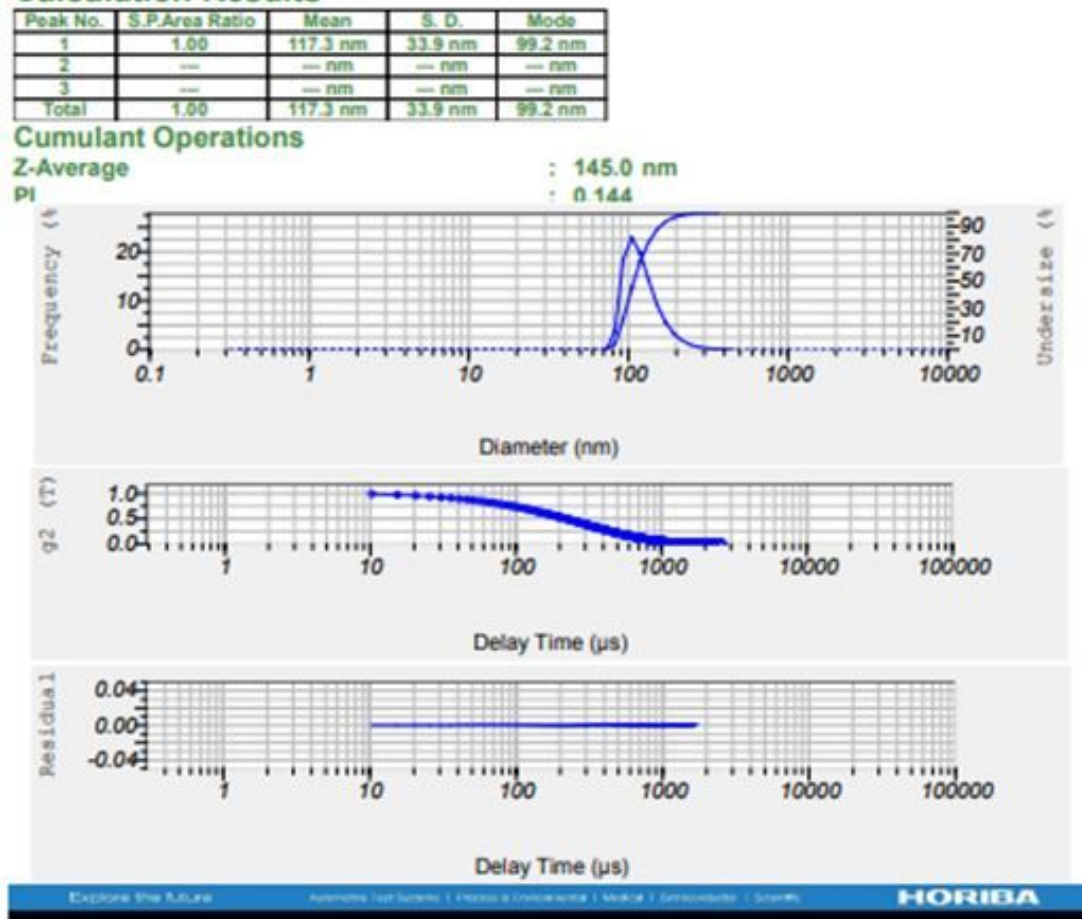

\section{Figure 1}

Size of the liposomal system containing essential oil of B. persicum

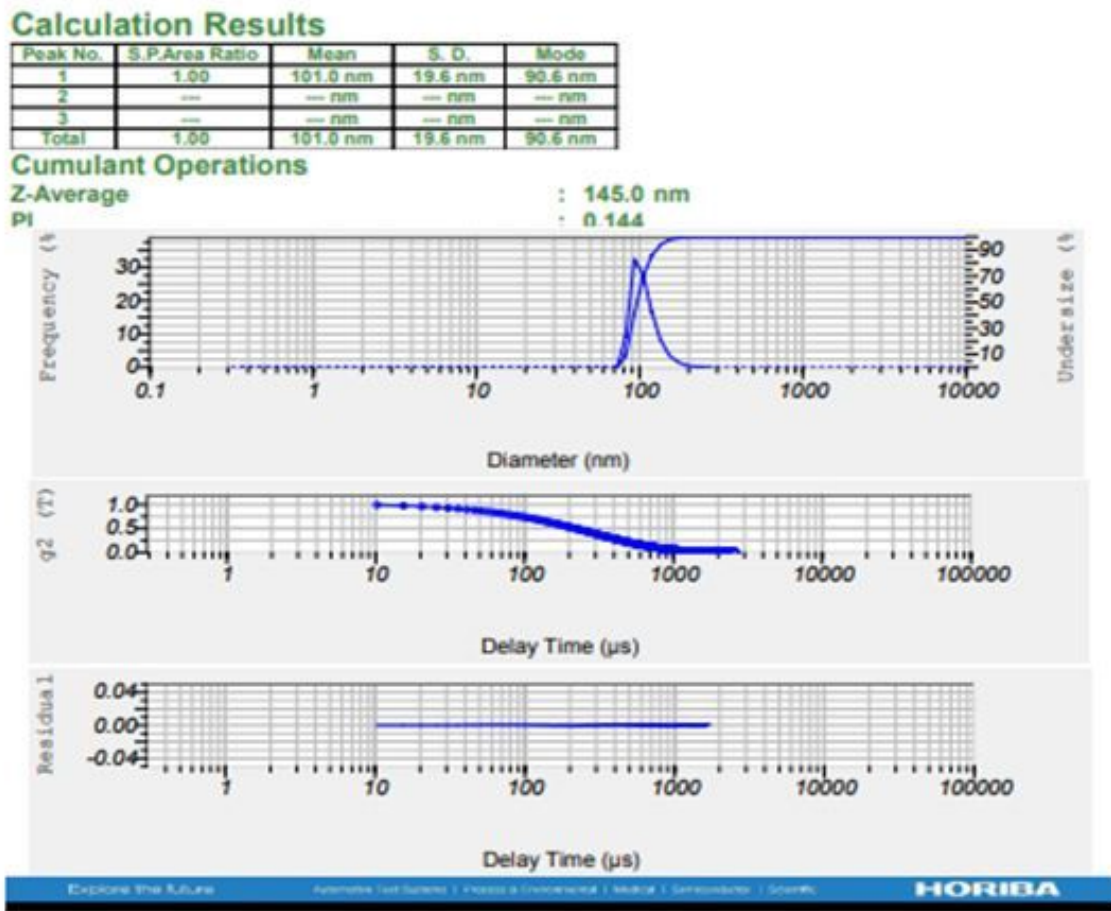

Figure 2

Size of the liposomal system containing essential oil of T. ammi 
HORIBA

\section{$S Z-100$}

\section{Measurement Results}

Measurement Results

Date

Mate

Sample Name

Temperature of the Holder

Dispersion Medium Viscosity

Conductivity

Electrode Voltage

Calculation Results

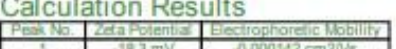

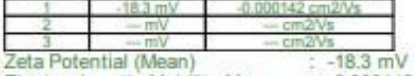

Electrophoretic Mobility Mean $\quad ;-0.000142 \mathrm{~cm} 2 / \mathrm{Vs}$

14December 2019 10:49:20

Zeta Potential

$25.1^{\circ} \mathrm{C}$

$0.893 \mathrm{mPa} \cdot \mathrm{s}$

$0.973 \mathrm{mS} / \mathrm{cm}$

$3.3 \mathrm{~V}$

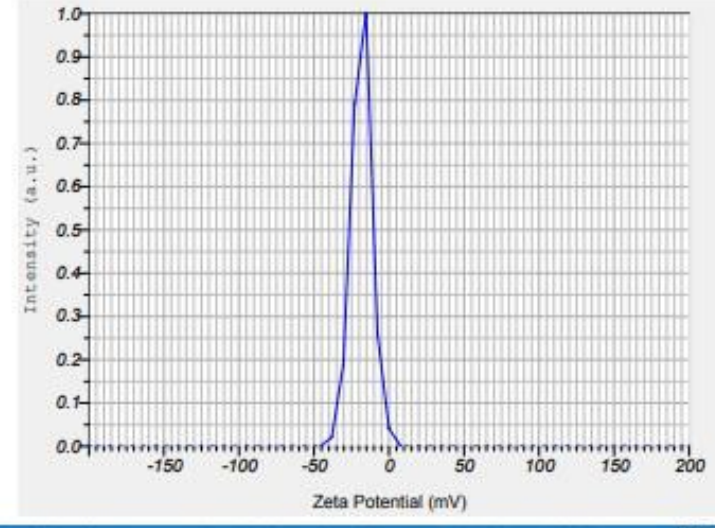

Horman

Figure 3

Zeta potential of the liposomal system containing essential oil of B. persicum 


\section{SZ-100}

\section{Measurement Results}

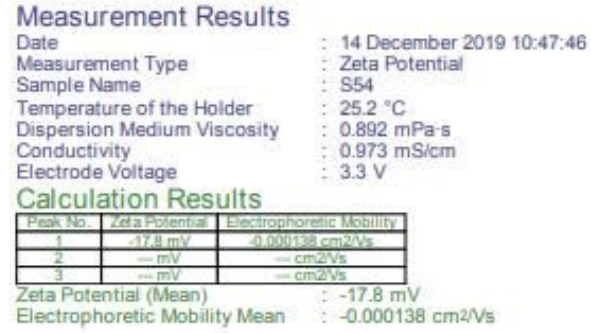

Electrophoretic Mobility Mean : $-0.000138 \mathrm{~cm} 2 / \mathrm{Vs}$

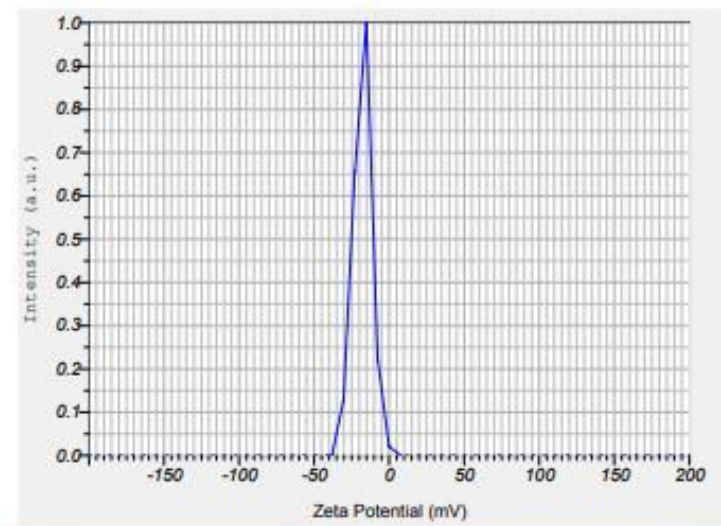

\section{Figure 4}

Zeta potential of the liposomal system containing essential oil of T. ammi 


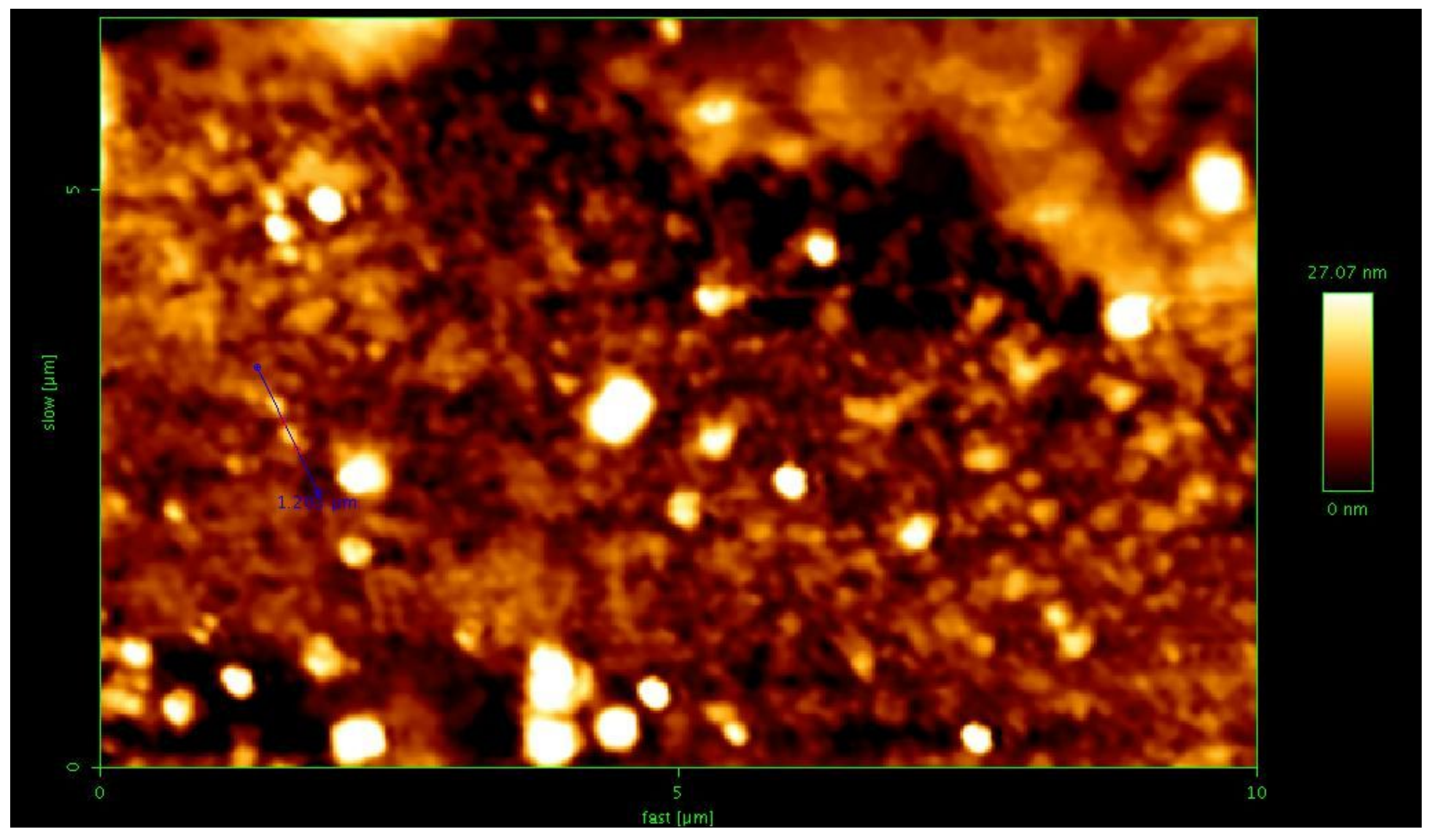

\section{Figure 5}

Atomic Force Microscope (AFM) photograph of liposomal system containing essential oil of B. persicum
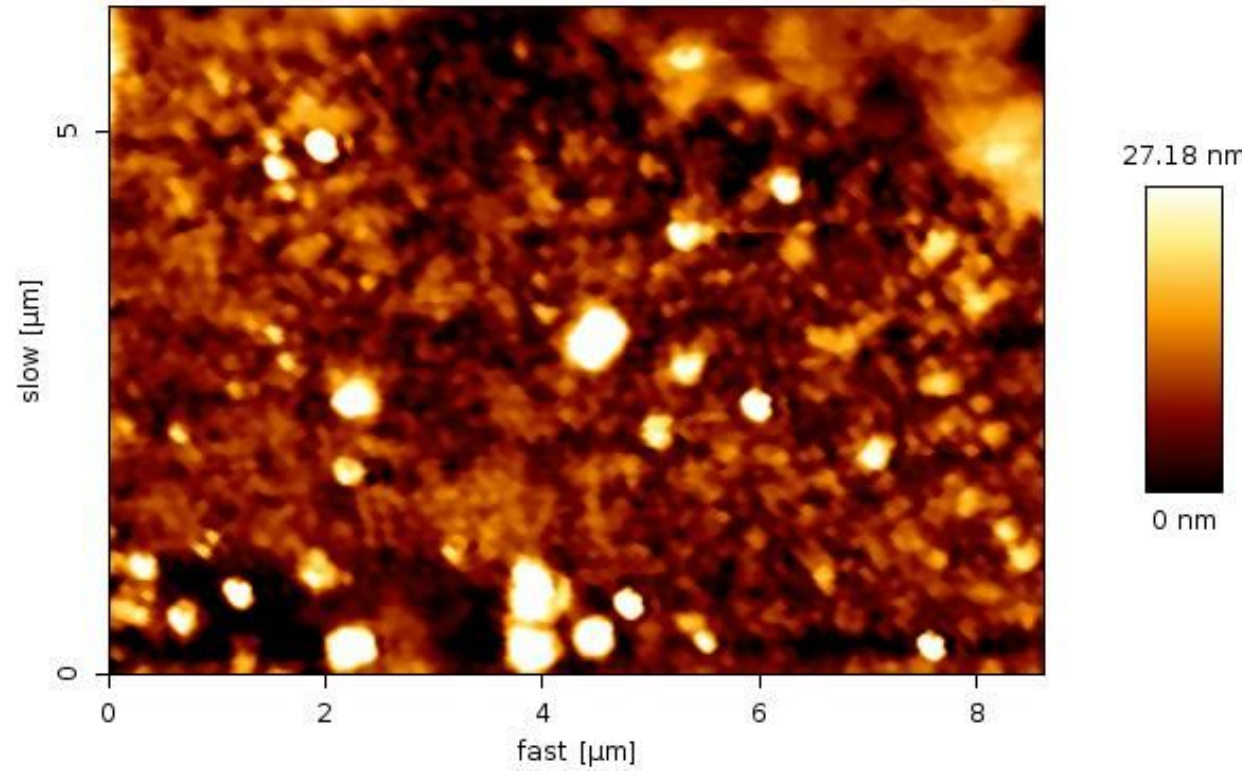

$0 \mathrm{~nm}$

Figure 6

Atomic Force Microscope (AFM) photograph of liposomal system containing essential oil of T. ammi 

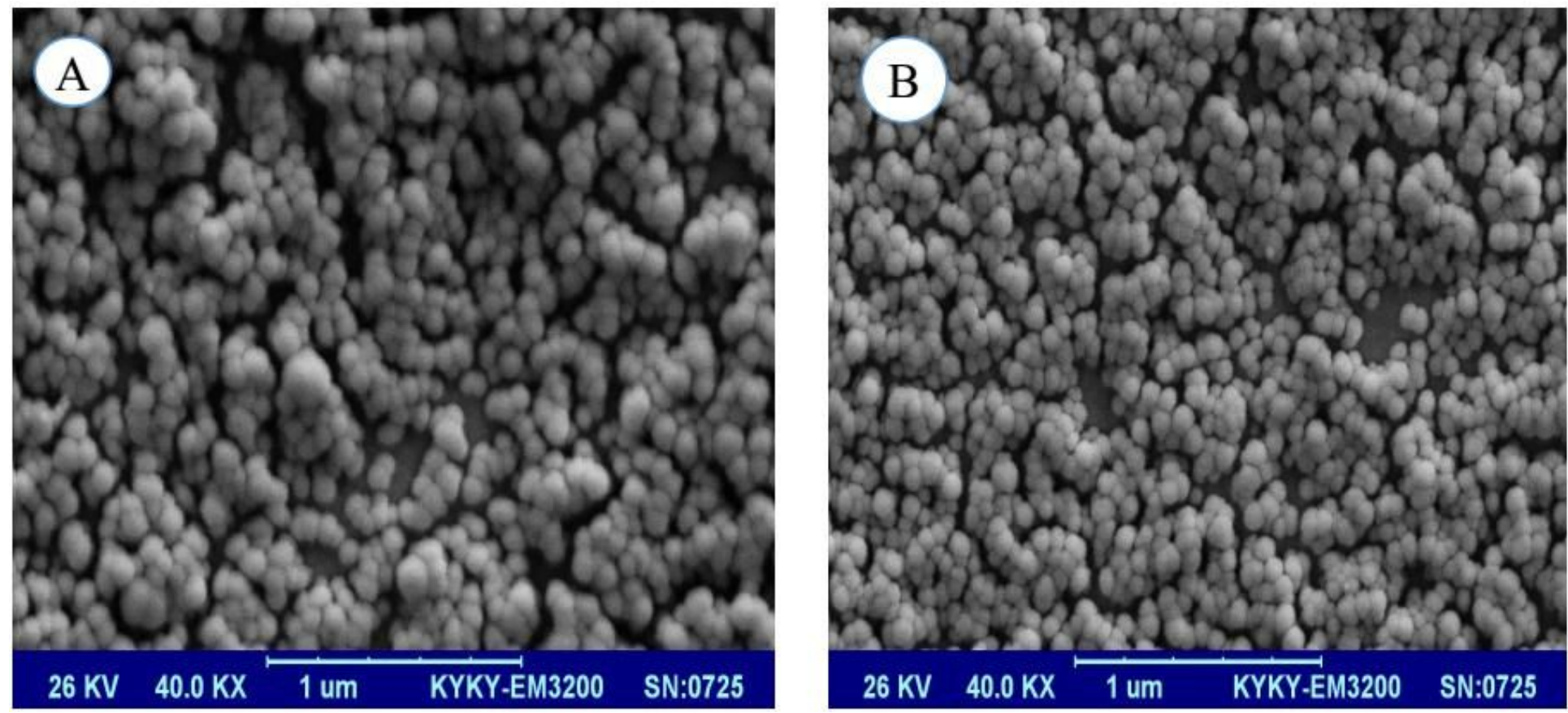

\section{Figure 7}

Scanning Electron Microscope (SEM) photograph of liposomal system containing essential oil of B. persicum; B. SEM photograph of liposomal system containing essential oil of T. ammi

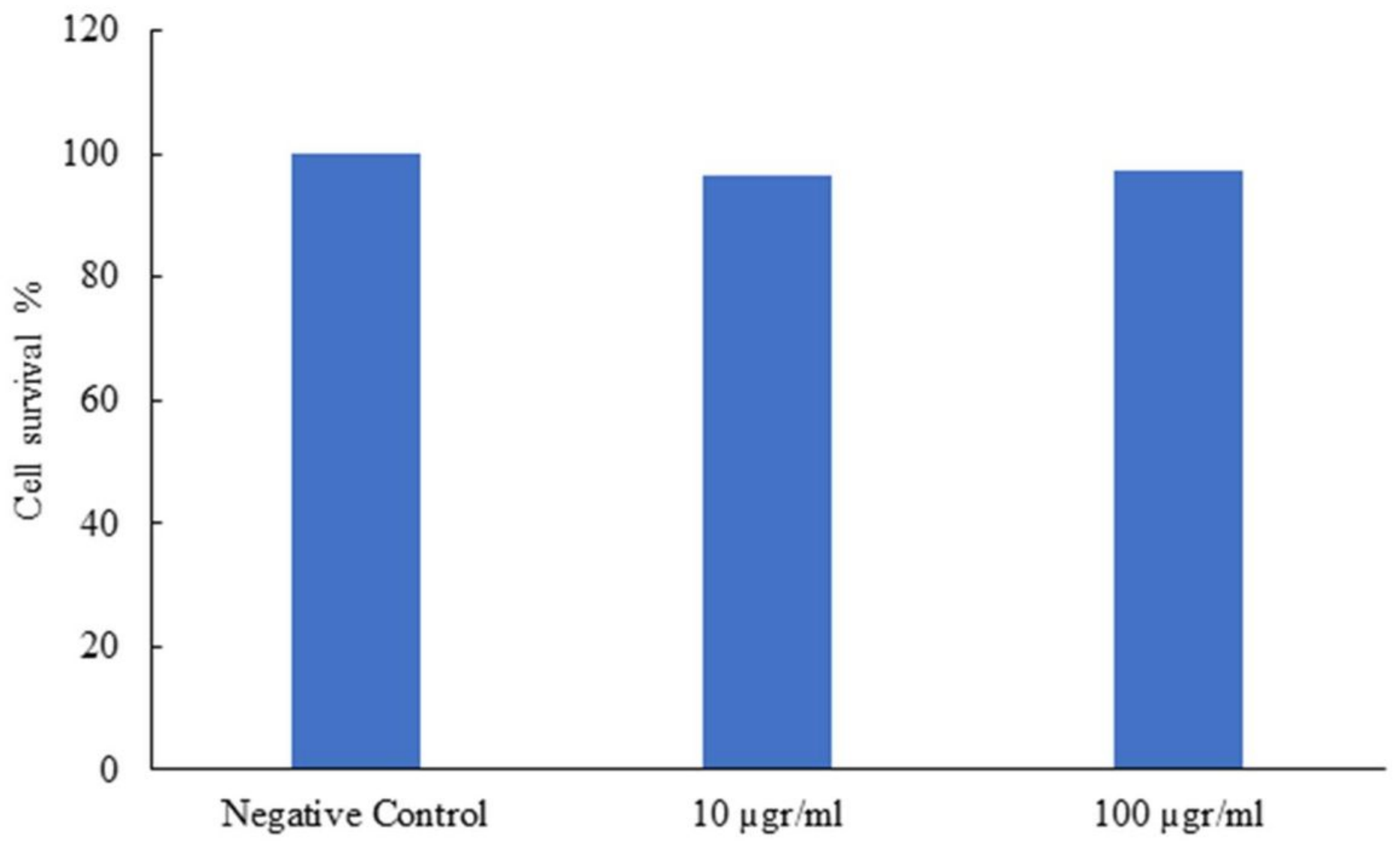

Concentration 
Figure 8

Toxicity of free liposomal system on Human foreskin fibroblast (HFF) at 48 hours

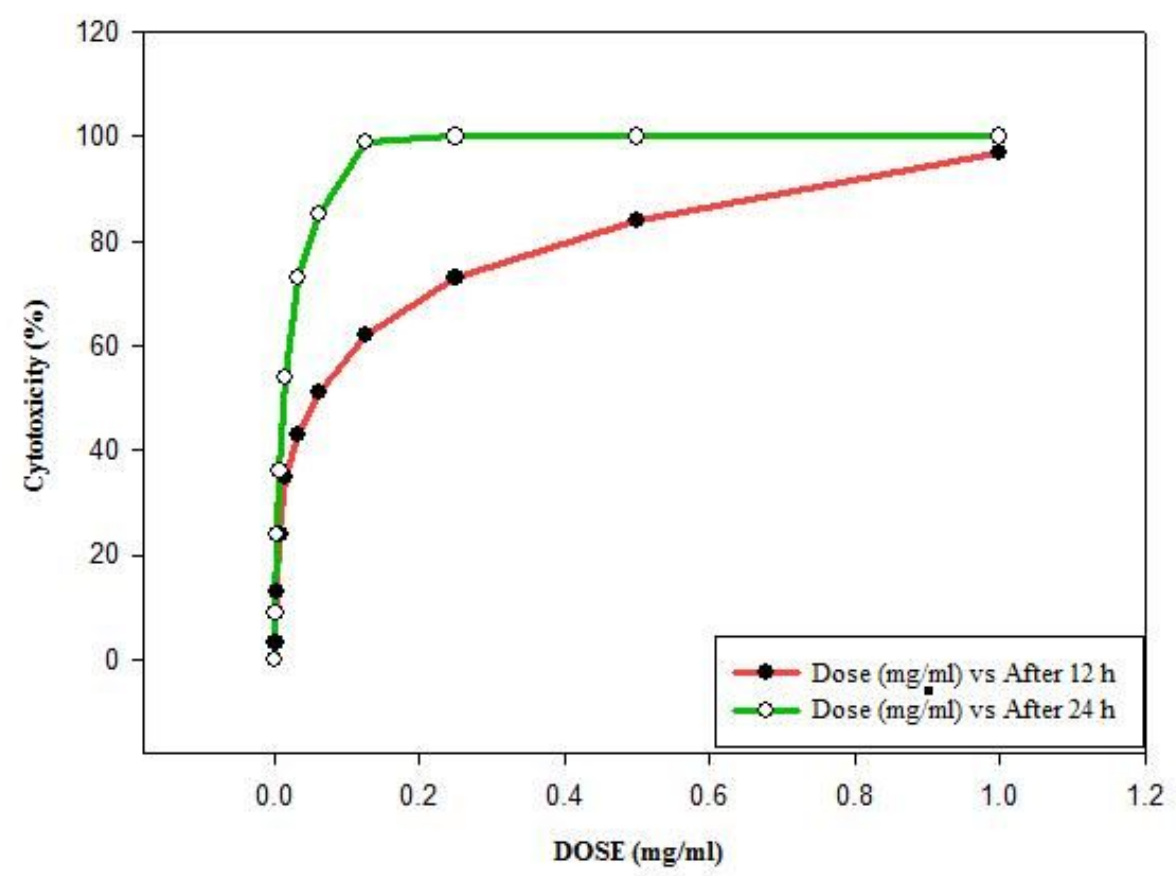

Figure 9

IC50 content of nano-liposomes containing essential oil of B. persicum against T. vaginalis after 12 and 24 hour incubation.

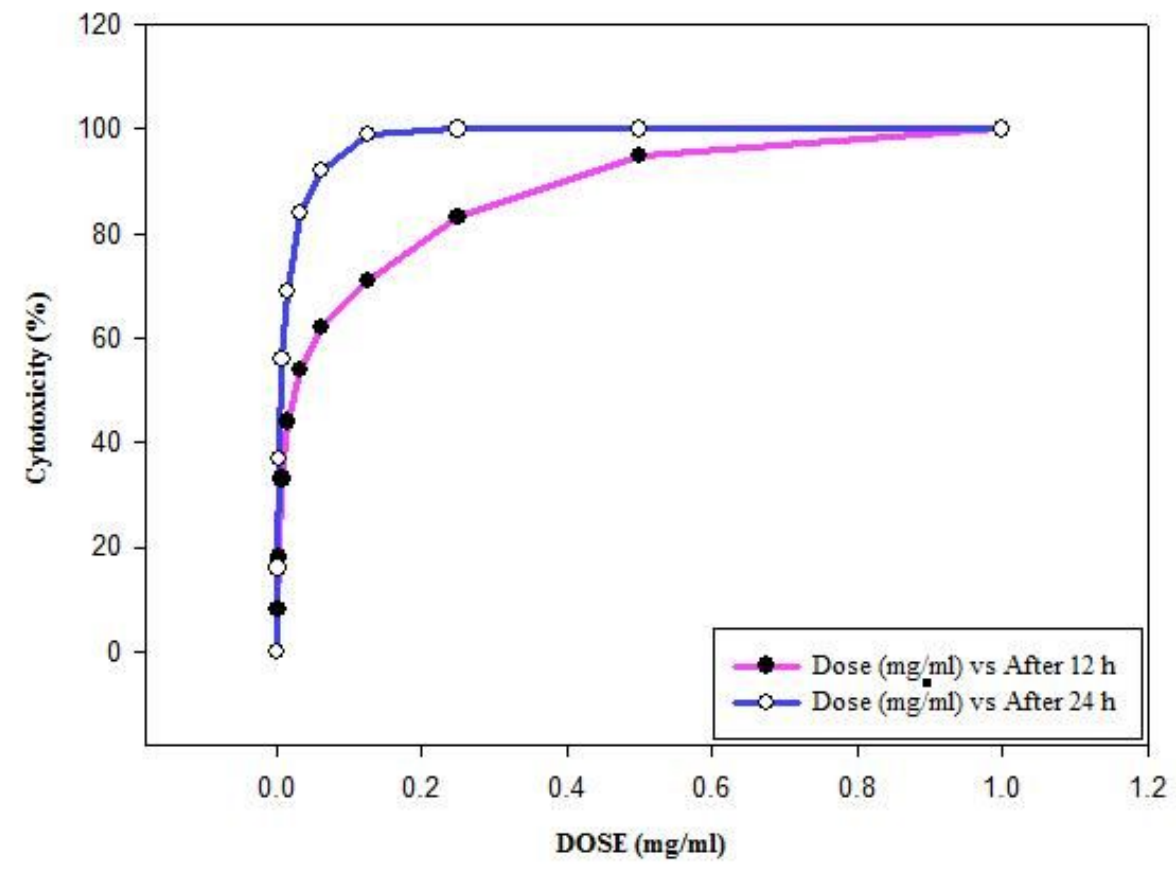

\section{Figure 10}

IC50 content of nano-liposomes containing essential oil of T. ammi against T. vaginalis after 12 and 24 hour incubation. 


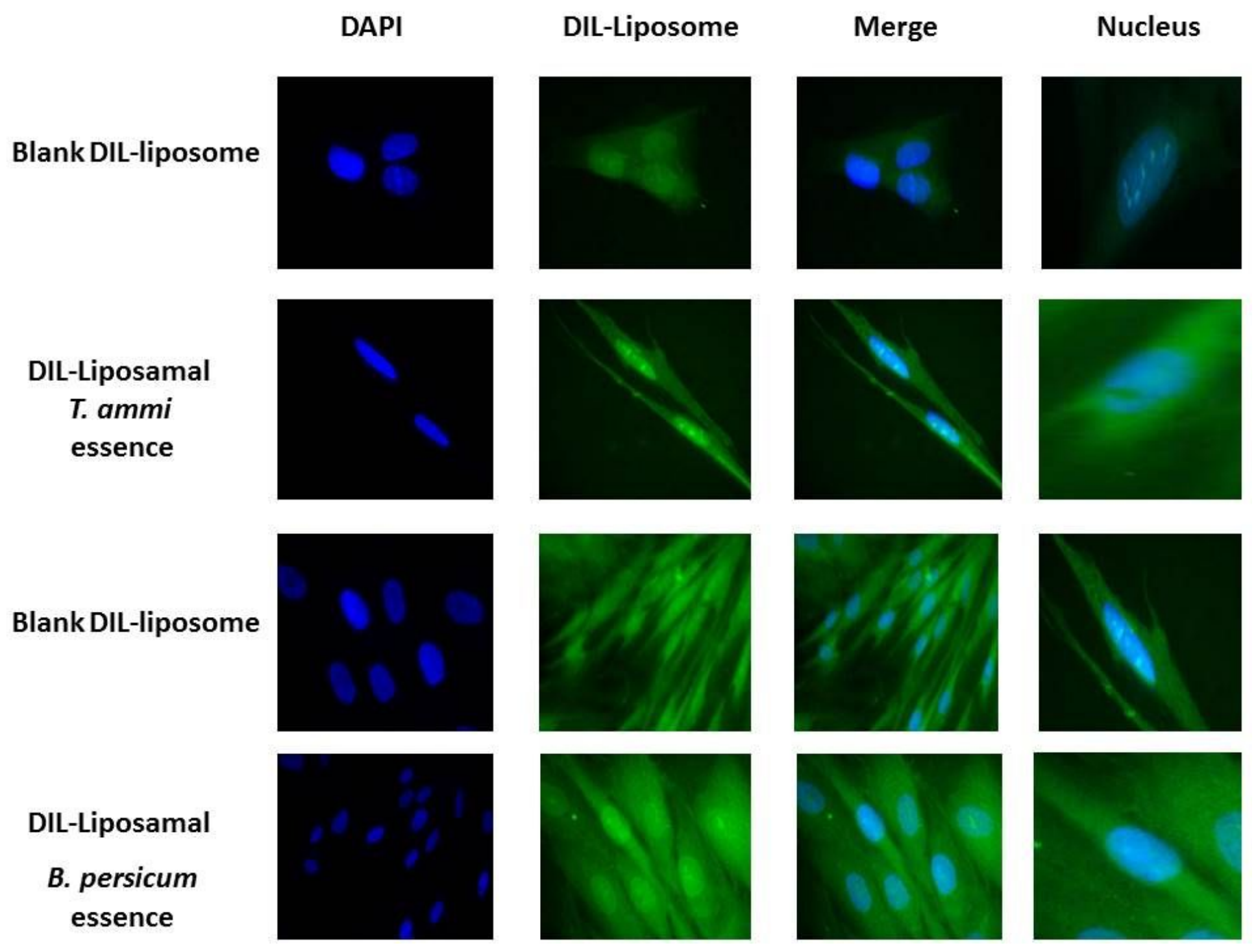

Figure 11

Fluorescent microscopic images of cellular uptake of nano-liposomes containing essential oils of T. ammi and B. persicum by human foreskin fibroblast under magnification of 400X. Abbreviations: DAPI, 6,4-diamidino-2-phenylindole; DIL, tetramethylindocarbocyanine perchlorate.

\section{Supplementary Files}

This is a list of supplementary files associated with this preprint. Click to download.

- Supplementarydata.docx 